\title{
Philosophiques
}

\section{Remerciements à nos lecteurs}

Volume 13, numéro 1, printemps 1986

URI : https://id.erudit.org/iderudit/203316ar

DOI : https://doi.org/10.7202/203316ar

Aller au sommaire du numéro

Éditeur(s)

Société de philosophie du Québec

ISSN

0316-2923 (imprimé)

1492-1391 (numérique)

Découvrir la revue

Citer ce document

(1986). Remerciements à nos lecteurs. Philosophiques, 13(1), 199-199.

https://doi.org/10.7202/203316ar

Ce document est protégé par la loi sur le droit d'auteur. L'utilisation des services d'Érudit (y compris la reproduction) est assujettie à sa politique d'utilisation que vous pouvez consulter en ligne.

https://apropos.erudit.org/fr/usagers/politique-dutilisation/
Cet article est diffusé et préservé par Érudit.

Érudit est un consortium interuniversitaire sans but lucratif composé de l’Université de Montréal, l'Université Laval et l'Université du Québec à Montréal. Il a pour mission la promotion et la valorisation de la recherche. https://www.erudit.org/fr/ 


\section{REMERCIEMENTS À NOS LECTEURS}

Depuis le $1^{\text {er }}$ janvier 1983, les personnes suivantes ont accepté d'évaluer des textes pour Philosophiques. Nous les en remercions vivement.

\author{
AUDET, Jean-Paul \\ AYOUB, Josiane \\ ARNOLD, Keith \\ ARONOVITCH, Hilliard \\ BAZAN, Carlos \\ BLAIS, Martin \\ BLAIS, Michel \\ BOUCHARD, Guy \\ CARIGNAN, Maurice \\ CARNOIS, Bernard \\ CHABOT, Marc \\ CHARRON, Ghislain \\ CHENE, Adèle \\ CHARNET, Mercedès \\ CLOUTIER, Yvan \\ DE BUJANDA, Jesus \\ DUCHESNEAU, François \\ DUMONT, Fernand \\ GAGNE, Paul \\ GARCEAU, Benoît
}

\author{
GERAETS, Théodore \\ GIROUX, Laurent \\ GRONDIN, Jean \\ HÉLAL, Georges \\ KAUFMANN, Nicolas \\ KING-FARLOW, John \\ KLIMOV, Alexis \\ LACHARITÉ, Normand \\ LAGUEUX, Maurice \\ LEGAULT, Georges \\ LEMAY, Diane \\ LEROUX, Georges \\ LEROUX, Jean \\ LETOCHA, Danièle \\ LEVESQUE, Claude \\ LUC, Laurent-Paul \\ MONTPETIT, Raymond \\ MARCIL-LACOSTE, Louise \\ McCALL, Storrs
}

\author{
McCORMICK, Peter \\ McKINNON, Alastair \\ MENDENHALL, Vance \\ MEUNIER, Jean-Guy \\ MIGUELEZ, Roberto \\ MORIN, Serge \\ NADEAU, Robert \\ PANACCIO, Claude \\ PAQUET, Léonce \\ PARADIS, André \\ PESTIEAU, Joseph \\ PUCETTI, Roland \\ RENAULT, Marc \\ RIOUX, Bertrand \\ SAINT-ARNAUD, Pierre \\ TCHAO, Joseph \\ TREMBLAY, Robert \\ VANDERVEKEN, Daniel \\ VALCKE, Louis
}

